\title{
Partial monosomy of chromosome 10 short arms
}

\author{
A GENČÍK*, U BRÖNNIMAN†, R TOBLER†, AND P AUF DER MAUR* \\ From *Zytogenetisches Labor, Pathologisches Institut der Universität, Bern; and \\ $\dagger$ Säuglingsspital Elfenau, Bern, Switzerland.
}

SUMmaRY Two children with monosmy $10 \mathrm{p} 13$ are reported. In the first case the monosomy was the result of a maternal balanced translocation $\mathrm{t}(3 ; 10)(\mathrm{p} 27 ; \mathrm{p} 13)$ while the second case was a de novo mutation. We reviewed clinical details of cases reported so far and found that certain symptoms are typical of the deletion of a comparatively large segment of chromosome 10 short arms. These symptoms include mental and growth retardation, skull abnormalities, antimongoloid slant of the eyes, ear abnormalities, anteverted nostrils, abnormalities of the hands and feet, cryptorchidism in boys, and, primarily, hypoplasia or aplasia of the olfactory bulbs and olfactory tracts as well as narrow palpebral fissures or eyelid ptosis.

Since the first description by Elliott et $a l^{1}$ of a probable partial deletion of $10 \mathrm{p}$ in a child with many clinical symptoms, a number of reports of patients with 10p partial monosomy have been published, ${ }^{2-7}$ thus enlarging the clinical picture.

Deletion of part of the chromosome 10 short arms associated with deletion of the long arm terminal segment is also found in cases with ring chromosome $10 .^{8-12}$ As a rule, the deletion of both telomeric segments is small and the clinical picture is not as severe as in cases of the above mentioned 10p partial monosomy.

Defined chromosome abnormalities, particularly monosomies, are suitable material for human genome mapping. Two enzyme loci have been thought to be located on $10 \mathrm{p}$, namely red blood cell hexokinase $\left(\mathrm{HK}_{1}\right)$ and pyrophosphatase (inorganic) (PF)..$^{1314}$

\section{Case reports}

FAMILY A (FIG 1)

The proband comes from a rural family of low intelligence who were reluctant to cooperate. The first (illegitimate) child (III.9) was born 10 days preterm in 1969. Birthweight was $2750 \mathrm{~g}$ and head circumference was $34.5 \mathrm{~cm}$. The infant had dysmorphic features including quadricephalic skull, low set and abnormally shaped ears, and aphony with normally formed epiglottis and normal larynx. A bifid uvula was also found. The eyes had an antimongoloid slant and there was micrognathia and anteverted nostrils. In addition, bilateral inguinal Received for publication 2 August 1982.

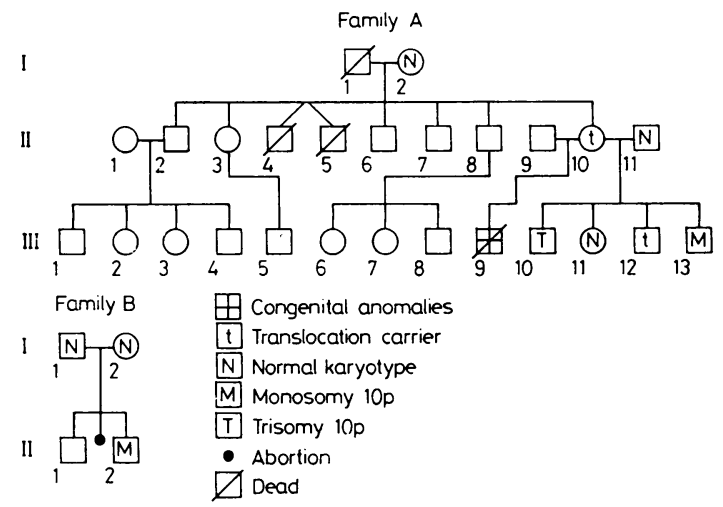

FIG 1 Pedigrees of the families with partial monosomy $10 p$.

hernia and cryptorchidism were found. Cytogenetic examination in the pre-banding era revealed an apparently normal male karyotype. The infant died suddenly at the age of 3 months. The second child (III.10), a boy with partial trisomy of chromosome 10 short arms, was born in 1971 . He showed retarded speech development at the age of 10 and minute cerebral motor defects, but development was normal and there were no dysmorphic features.

Case 1 (III.13)

This was the fifth child of the family. Delivery occurred 2 weeks before term. Birthweight was $2760 \mathrm{~g}$, length was $47 \mathrm{~cm}$, and head circumference was $34 \mathrm{~cm}$. During the postnatal period a very soft cry and trouble in sucking were noted. Examination 
at the clinic during the first month of life showed a dysmorphic syndrome with the following signs: quadricephalic skull with prominent forehead, broad skull sutures, abnormally shaped low set ears rotated backwards, flat nose bridge, anteverted nostrils, high palate, hypertelorism, ptosis, more pronounced on the left side, the forefinger crossing over the middle finger, and cryptorchidism. The infant's cry was soft and purring. Neurological examination showed overall muscular hypotonia as well as weak sucking and gripping reflexes. Abduction of the hips was limited. Congenital hypothyroidism was also found. Repeated EEG examinations showed normal findings although epileptiform spasms were observed from the 8th to the 18 th week of age. At the age of 14 months amblyopia associated with divergent strabismus was noted. Psychomotor development has been greatly retarded since the first examination.

Examination at the age of 4 years showed a clinical picture dominated by marked psychomotor and growth retardation. The child could not walk, contact was very poor, and no signs of speech were present. The mask-like face showed extremely



(a)

FIG 2 (a) Case 1 at 4 years of age. (b) Case 2 at 2 weeks of age.

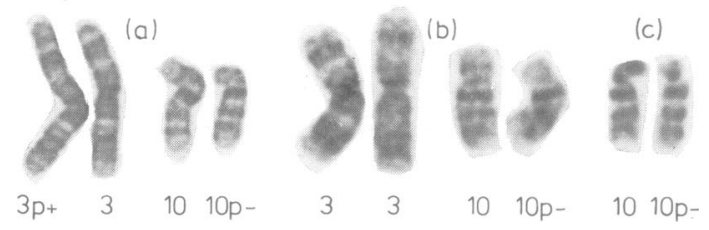

FIG 3 Partial karyotypes ( $G$ bands). (a) Mother of case 1 (family A, II.10) with translocation $t(3 ; 10)(p 27 ; p 13)$.

(b) Case 1 (family $A$, III.13) with del(10)(p13). (c) Case 2 (family B,II.2) with del(10)(p13). limited mobility and a constantly open mouth: he frequently ground his teeth. The skull was flattened at the sides and the face was asymmetrical. Ptosis was more prominent on the right side. Mild hypertelorism, divergent strabismus, and a beak-like nose with a flattened tip were observed. The alveolar arch of the maxilla was prominent and the teeth were abnormally formed. The chin slanted backwards, the ears were not fully formed and were small, rotated backwards, and very low set (fig 2a). The hair-line was low at the nape of the neck. Red blood cell hexokinase determinations gave normal values. Cytogenetic examination showed a karyotype of $46, X Y, \operatorname{del}(10)(p 13)$ (fig 3b).

\section{FAMILY B (FIG 1)}

The proband (case 2, II.2) was the third child of a 28-year-old mother and 36-year-old father. Delivery occurred 2 weeks after term. Birth weight was $2800 \mathrm{~g}$, length was $48 \mathrm{~cm}$, and head circumference was $35 \mathrm{~cm}$. Clinical examination revealed the following (fig $2 \mathrm{~b}$ ): hypertelorism, abnormally shaped low set large ears, rotated backwards, anteverted nostrils, micrognathia, short and thick neck, syndactyly of fingers 3 and 4 , clinodactyly, transverse creases on both palms, hypospadias, and cryptorchidism. Cardiological examination showed a developmental heart defect. The child had to be fed through a tube because of sucking difficulties. Despite intensive cardiac therapy, the congenital heart defect led to acute heart and respiratory failure, resulting in the death of the child on the 17th day of life. Cytogenetic examination revealed a terminal deletion in the chromosome 10 short arms with a break in band 10p13 (fig 3c).

\section{Discussion}

Stene and Stengel-Rutkowski ${ }^{15}$ analysed 11 families with familial translocations involving a segment of the short arm of chromosome 10, resulting in partial trisomy $10 \mathrm{p}$. However monosomy of the chromosome 10 short arms was not found in any member of the families. All six cases reported so far of partial monosomy $10 \mathrm{p},{ }^{2-7}$ as well as our second case, have arisen de novo. In contrast, all four segregation possibilities, including a child with partial monosomy $10 \mathrm{p}$, were found in our first family, that is, the children of a mother carrying a balanced translocation $t(3 ; 10)$. In this family, in addition to one child with a normal karyotype (fig 1) and one with the same balanced translocation as his mother, a third child, a boy, had trisomy of the distal segment of chromosome 10 short arms with severe clinical symptoms. The first child had a phenotype similar to that of his monosomic sib; thus he may have been carrying a 


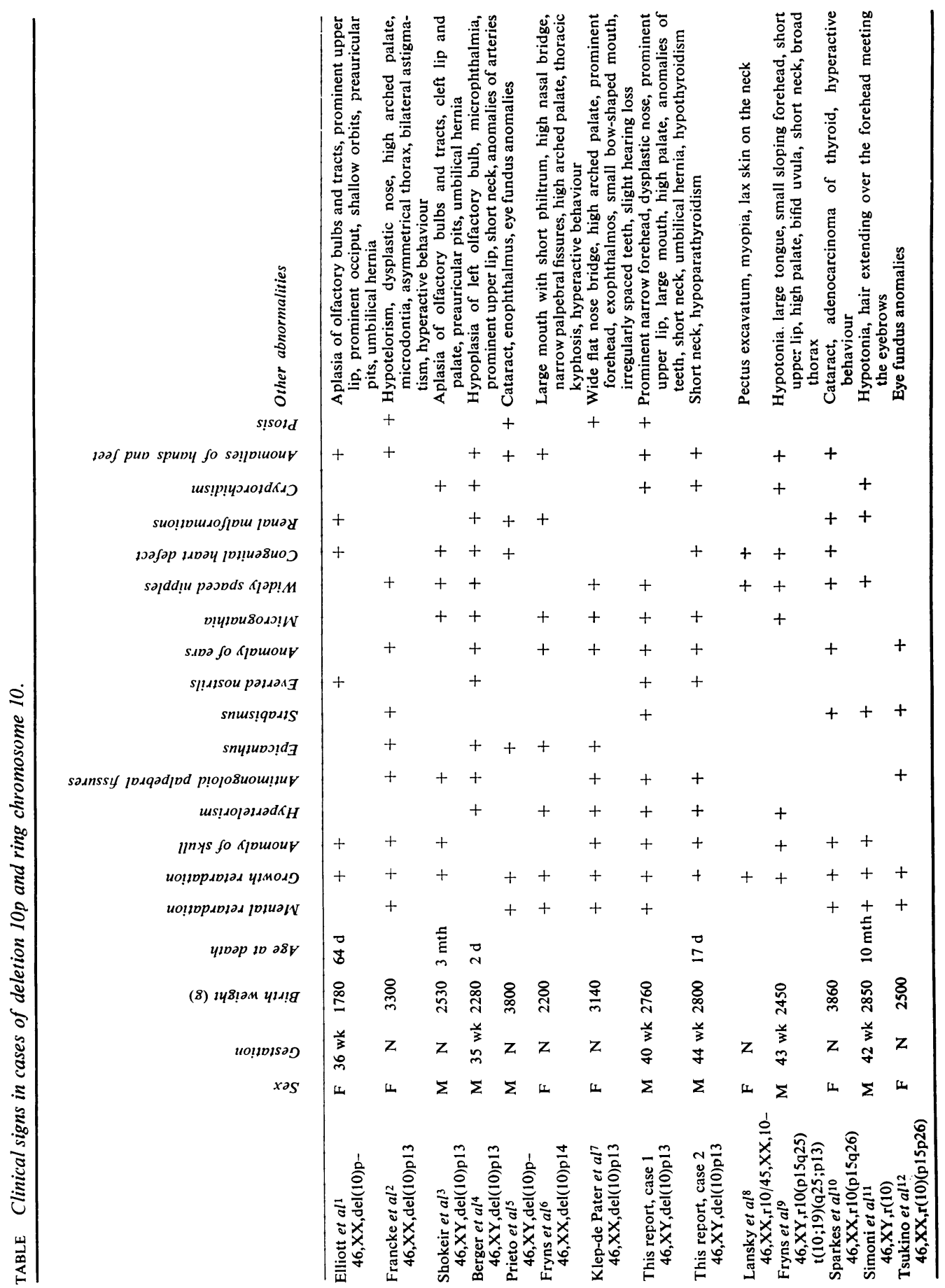


chromosome anomaly of the monosomy type, although trisomy cannot be excluded. The marked similarity of the clinical picture to that of his monosomic sib (quadricephalic head, weak cry, and sucking problems) and the presence of features like antimongoloid slant of the eyes and anteverted nostrils that do not occur in trisomy $10 \mathrm{p}^{16}$ would favour monosomy.

The fact that there are many more cases of trisomy $10 p$ than monosomy $10 p$ confirms the view that monosomy of a part of the genome usually results in more serious defects than trisomy of the same part. Most monosomic cases are probably eliminated in early embryonal life.

In the few reports of partial monosomy 10p, monosomy of the p13 $\rightarrow$ pter segment has been observed most frequently. ${ }^{2-4} 7$ The case reported by Prieto et $a l^{5}$ concerned an interstitial deletion limited to the segment 10p13; in the case of Fryns et $a^{6}{ }^{6}$ a terminal deletion 10 (p14 $\rightarrow$ pter) was observed. Both our cases of monosomy of the segment 10 (p13 $\rightarrow$ pter) confirm this to be the most frequent type of monosomy $10 \mathrm{p}$ seen. This may indicate a predominance of breakpoints in band p13.

Owing to the limited number of observations (table) it is difficult to draw more general conclusions concerning the phenotypic features of $10 p$ partial monosomy, since the symptoms are very variable and also frequently overlap with other chromosome abnormalities. Probably growth retardation associated with mental retardation in older children are the main signs. Antimongoloid slant of the eyes, associated with ptosis or narrow palpebral fissures or both, is typical to a certain extent. Abnormalities of the face, like hypertelorism, broad nose bridge, a peculiar shape to the nose, and anteverted nostrils are very frequent, the same being true for ear abnormalities, epicanthic folds, micrognathia, abnormalities of the hands and feet, and cardiac and urinary tract malformations. Cryptorchidism was noted in boys in four out of five cases. Four out of nine children died within the first 3 months of life. The frequent ophthalmological symptoms, including fundus anomalies, microphthalmia, astigmatism, and cataract, are noteworthy. In all three children so far examined post mortem, hypoplasia (once) or aplasia (twice) of the olfactory bulbs and tracts was observed. Hyperactive behaviour was found in two out of five living children.

For comparison, the lower half of the table summarises the phenotypic signs of five reported patients with a ring chromosome 10. Apart from some non-specific symptoms, signs occurring in pure partial deletions of $10 \mathrm{p}$ can also be seen. This is true for retardation in growth (five cases), widely spaced nipples (four cases), and strabismus (three cases), in addition to other symptoms. Again, one case showed hyperactive behaviour. Narrow palpebral fissures or ptosis were not present in any of the cases. It should; however, be pointed out that these signs are not usually observed until a certain age has been reached and of the 14 patients reported, six died in early childhood.

Based on the data in the table and on an analysis of the clinical symptoms, association of phenotypic signs with deletion of certain chromosome segments may be suspected. In deletions of the more proximal segments 10p13 and 10p14, hypoplasia or aplasia of the olfactory bulbs and olfactory tracts, as well as narrow palpebral fissures or ptosis or both, have been observed in addition to a number of other relatively frequent symptoms. These signs have not been reported in cases of terminal deletion (ring chromosome). In contrast, strabismus and widely spaced nipples may be seen in patients with deletion of the terminal segment of $10 \mathrm{p}$ as well as a larger part of $10 \mathrm{p}$; this suggests a possible association of these symptoms with deletion of the terminal segment of $10 \mathrm{p}$.

\section{References}

1 Elliott D, Thomas GH, Condron CJ, Khuri N, Richardson F. C-group chromosome abnormality (? 10p-). Am J Dis Child 1970; 119:72-3.

2 Francke U, Kernahan C, Bradshae Ch. Del (10)p autosomal deletion syndrome: clinical, cytogenetic and gene marker studies. Hum Genet 1975; 26:343-51.

3 Shokeir MHK, Ray M, Hamerton JL, Bauder F, O'Brien H. Deletion of the short arm of chromosome No 10. J Med Genet 1975;12:99-113.

4 Berger R, Larroche JC, Toublas PL. Deletion of the short arm of chromosome No 10. Acta Paediatr Scand 1977;66: 659-62.

5 Prieto F, Badia L, Moreno JA, Barbero P, Asensi F. $10 \mathrm{p}$ - syndrome associated with multiple chromosomal abnormalities. Hum Genet 1978; 45 :229-35.

6 Fryns JP, De Mealenaere A, van den Berghe H. Distal 10p deletion syndrome. Ann Genet (Paris) 1981; 24:18990.

7 Klep-de Pater JM, Bijlsma JB, Alkema FMJ. Partial monosomy 10p syndrome. Eur J Pediatr 1981 ;137:243-6.

8 Lansky S, Daniel W, Fleiszar K. Physical retardation associated with ring chromosome mosaicism: 46,XX, r(10)/45, XX,10-. J Med Genet 1977; 14:61-3.

9 Fryns JP, De Boeck K, Jaeken J, van den Berghe $\mathbf{H}$. Malformation syndrome associated with a ring 10 chromosome and a translocated 10q/19 chromosome. Hum Genet 1978;43:239-44.

10 Sparkes RS, Ling SM, Muller H. Ring 10 chromosome: 46, XX, r10 (p15q26). Hum Genet 1978; 43:341-5.

11 Simoni G, Rossella F, Dalpra L, Visconti G, PiriaSchwarz C. Ring chromosome 10 associated with multiple congenital malformations. Hum Genet 1979;51:117-21.

12 Tsukino R, Tsuda N, Dezawa T, Ishii T, Koike M. Ring chromosome 10: 46,XX,r(10)(p15q26). J Med Genet $1980 ; 17: 148-51$. 
13 de la Chapelle A, Miller OJ. Report of the committee on the genetic constitution of chromosome 10,11,12, $\mathrm{X}$ and Y. Cytogenet Cell Genet 1979; 25:47-58.

14 Dallapiccola B, Chessa L, Vignetti P, Ferranta E, Gandini E. Increased $\mathbf{H K}_{1}$ activity levels in the red cells of a patient with a de novo trisomy $10 \mathrm{p}: \mathrm{t}(\mathrm{Y} ; 10)(\mathrm{p} 11 ; \mathrm{p} 12)$. Hum Genet 1979; 50:45-9.

15 Stene J, Stengel-Rutkowski S. Risk for short arm 10 trisomy. Hum Genet 1977; 39:7-13.
16 Lurie IW, Lazjuk GI, Gurevich DB, Kravtzova GI, Nedzved MK, Shved IA. Partial trisomy $10 \mathrm{p}$ in two generations. Hum Genet $1978 ; 41: 235-41$.

Requests for reprints to Dr A Genčík, Humangenetik, Dept Forschung, Kantonsspital, 4031 Basel, Switzerland. 